IdeAs

Idées d'Amériques

$10 \mid 2017$

États-Unis / Cuba : une nouvelle donne?

\title{
Opciones para las relaciones entre Cuba y Estados Unidos durante la presidencia de Donald Trump
}

Options for U.S.-Cuban relations during the Donald Trump Presidency Les relations entre Cuba et les Etats-Unis pendant la présidence de Donald Trump: quelles options?

Jorge I. Domínguez

\section{OpenEdition}

Journals

Edición electrónica

URL: https://journals.openedition.org/ideas/2139

DOI: 10.4000/ideas.2139

ISSN: 1950-5701

Editor

Institut des Amériques

Referencia electrónica

Jorge I. Domínguez, «Opciones para las relaciones entre Cuba y Estados Unidos durante la presidencia de Donald Trump», IdeAs [En línea], 10 | 2017, Publicado el 19 diciembre 2017, consultado el 18 octubre 2022. URL: http://journals.openedition.org/ideas/2139; DOI: https://doi.org/10.4000/ ideas. 2139

Este documento fue generado automáticamente el 18 octubre 2022

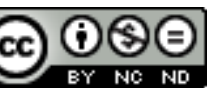

Creative Commons - Atribución-NoComercial-SinDerivadas 4.0 Internacional - CC BY-NC-ND 4.0 https://creativecommons.org/licenses/by-nc-nd/4.0/ 


\section{Opciones para las relaciones entre Cuba y Estados Unidos durante la presidencia de Donald Trump}

Options for U.S.-Cuban relations during the Donald Trump Presidency Les relations entre Cuba et les Etats-Unis pendant la présidence de Donald Trump: quelles options?

Jorge I. Domínguez

\section{Introducción: ¿Relaciones sin importancia?}

1 El prólogo de la historia de la política hacia Cuba de la presidencia de Donald Trump, evidente durante sus primeros meses en la Casa Blanca, indicaba que Cuba representaba un asunto de tercera categoría, mucho menos importante que algún otro tema, nacional o internacional, que ocupaba, para bien o para mal, la atención de este presidente. Durante sus primeros meses en la presidencia, según el buscador electrónico en la página web de la Casa Blanca, Cuba aparecía mencionada con relación a cuatro temas:

- ¿Cuál fue la política del Presidente Franklin Pierce hacia Cuba a mediados del Siglo XIX?

- ¿Cuál fue la política del Presidente William McKinley hacia Cuba para fines del Siglo XIX?

- ¿Cuál fue la política del Presidente John Kennedy hacia Cuba en los 1960s?

- Muy breves referencias a que la política del Presidente Donald Trump hacia Cuba seguía bajo estudio, y que cuando fuera anunciada trataría entre otras cosas el tema de derechos humanos.

Mientras tanto el Presidente Trump se ocupaba de otros asuntos, entre otros el despido de su primer asesor de Seguridad Nacional y de su director del Buró Federal de Investigaciones (FBI), el repudio del Tratado de París sobre cambio climático y del acuerdo comercial trans-Pacífico. Un factor que retardaba la toma de decisiones sobre diversas cuestiones fue el rezago en sus nombramientos de quienes serían responsables 
de los niveles de mando intermedio en su Administración, lo que evidentemente dificultó la inmediata elaboración de nuevas políticas, entre otras de su nueva política hacia Cuba.

Si descendemos de la muy personal política presidencial, sin embargo, ya estaba en marcha una política hacia Cuba, y ya se podía comenzar a discernir las opciones frente al futuro. En este artículo, describo la relación en materia de seguridad y migración entre Cuba y Estados Unidos, que es tan estrecha, precisa, y perdurable que la caracterizo como una alianza. Repaso la ampliación de la cooperación entre Cuba y Estados Unidos durante la Administración Obama, señalando que las ventajas de estos acuerdos fueron compartidas y en algunos casos desproporcionadamente favorecieron a Estados Unidos. Me detengo en la reaparición de un conflicto ideológico en torno a democracia y derechos humanos, cristalizados por el Presidente Trump en su anuncio de modificación parcial de política hacia Cuba. Exploro las opciones próximas en estas relaciones bilaterales, concluyendo que Estados Unidos posee espacio de maniobra para reanudar su énfasis en el tema de derechos humanos ya que es improbable que Cuba prefiera sacrificar los logros de colaboración en seguridad, migración, o relaciones económicas. Esto le permitirá al Presidente Trump gozar de un triunfo simbólico, posiblemente incluyendo la ruptura de relaciones diplomáticas, cumpliendo sus promesas de campaña de revertir la política de la Administración Obama hacia Cuba.

\section{La alianza Cuba-EEUU: seguridad y migración}

Durante más de veinte años, Cuba y Estados Unidos han desarrollado una estrecha coordinación $\mathrm{y}$, ya en varios aspectos, de cooperación, principal aunque no exclusivamente sobre asuntos de seguridad y migración. Durante su campaña presidencial y sus primeros meses en la Casa Blanca, Donald Trump subrayó que, en términos generales, la seguridad era una de sus prioridades como presidente. Con relación a la prisión en la base de Estados Unidos cerca de Guantánamo, la migración, el narcotráfico, y el terrorismo, visto desde la perspectiva y las preferencias de Donald Trump, Cuba es un aliado ejemplar que, si bien por sus propias razones, hace lo que Trump desea que Cuba haga.

5 Guantánamo. Cuba no reconoce la legitimidad de la presencia de la base naval de EEUU cerca de Guantánamo, pero ha aceptado su uso como prisión de EEUU. En enero de 2002, Cuba reconoció que EEUU con antelación comunicó una información pertinente y detallada sobre las medidas de seguridad en la base y su perímetro, que entre otros efectos protegían la seguridad de Cuba. El Presidente Fidel Castro y el Presidente George W. Bush autorizaron la cooperación militar para consolidar una relación de seguridad mutua, manteniendo un régimen profesional de consultas militares bilaterales, preservando el ambiente de distensión y respeto mutuo que así se fortalecía. El General Raúl Castro ese mismo mes confirmó esta cooperación entre militares en el entorno de la base, y su anterior existencia parcial desde la Administración Clinton, indicando la disposición de Cuba para ampliar estos marcos de cooperación militar («Statement by the Government of Cuba, 2002; Castro Ruz R., 2002).

La coordinación militar en el entorno de esa base entre las fuerzas armadas de ambos países ha continuado durante la Administración Trump, sin mayor novedad. El Presidente Trump ha indicado que, a diferencia de su predecesor, no intentará cerrar la 
prisión en la base, y por tanto seguirá siendo útil esta relación con Cuba por un futuro indefinido.

7 Migración. Durante su campaña presidencial, y desde su elección, Trump insistió que los asuntos migratorios son prioritarios. Desde 1995, Cuba y EEUU cooperaron con precisión y detalle para impedir flujos migratorios indocumentados a través del Estrecho de la Florida y controlar los flujos documentados. Las autoridades cubanas han hecho lo posible por evitar el robo de embarcaciones $u$ otros transportes que faciliten la migración indocumentada. Exigen la presentación de visas emitidas por el país de destino antes de abordar un avión en aeropuerto cubano. Cooperan los Guardafronteras y los Guardacostas en el Estrecho de Florida para rescatar a quienes intenten cruzar en embarcaciones endebles. Permiten que buques Guardacostas de EEUU, que han apresado a indocumentados en el medio de ese intento de cruce, arriben a puerto cubano para devolver a esos migrantes potenciales, que Cuba entonces acepta. Durante el transcurso de este siglo, un alto oficial de los Guardacostas de EEUU ha estado ubicado en La Habana para coordinar esta relación migratoria, y de seguridad marítima, y combate al narcotráfico. Cuba ha demostrado su disposición y capacidad de cooperar eficazmente con la política migratoria preferida por el Presidente Trump. Esta cooperación migratoria bilateral comenzó durante las presidencias de Fidel Castro y William Clinton, y persistió bajo Raúl Castro, George W. Bush, Barack Obama, y ahora Donald Trump.

8 Esa cooperación, sin embargo, no cubría cubanos indocumentados que llegaban a EEUU por avión o por tierra, inclusive cruzando a pie la frontera entre México y EEUU. El 12 de enero de 2017, el gobierno de EEUU canceló su anterior política migratoria, conocida como de «pies secos/pies mojados.» Desde 1995, esa política permitía a cualquier cubano, sin visa u otro documento migratorio, que tocara tierra firme en EEUU, quedarse en EEUU bajo asilo político; sin embargo, quienes fueran interceptados en alta mar por un Guardacostas de EEUU, eran regresados a puerto cubano. Utilizando la autorización inherente en la Ley de Ajuste Cubano de 1966, el Presidente Barack Obama ordenó a su ministro de Justicia que dejara de ejercer la potestad de excepcionalidad con relación a migrantes cubanos que esa Ley permite al Ejecutivo (Public Law 89-732, 1966: 1161). Sin necesidad de acudir al Congreso, se suspendió su aplicación por Orden Ejecutiva, obligando a todo cubano que desee ingresar a EEUU que lo haga mediante la ley de inmigración que se aplica a los ciudadanos de todos los demás países. Ese cambio, si bien lamentable desde la perspectiva de un posible migrante cubano, por muchos años había sido un reiterado reclamo del Gobierno de Cuba.

Ese mismo día, un comunicado conjunto de los gobiernos de Cuba y EEUU, firmado en La Habana, estableció un nuevo marco de cooperación. Todo cubano indocumentado que después de la firma de este comunicado conjunto intentara entrar en EEUU, o que ya había entrado, sería devuelto a Cuba, que los aceptaría a todos. Además, Cuba indicó que consideraría, caso por caso, el retorno de otros indocumentados cubanos capturados por las autoridades de EEUU antes de la firma de este nuevo acuerdo (U.S. Department of Homeland Security, 2017).

10 La coordinación y cooperación migratoria ha continuado durante la Administración Trump. Es lógico que así sea. El gobierno de Cuba coopera con EEUU tanto para impedir la salida de su territorio de sus ciudadanos cuando sean carentes de documentos para entrar a EEUU -cosa que no hace ningún otro gobierno en el continente americanocomo para permitir la devolución de los indocumentados mediante cooperación 
profesional entre las fuerzas de seguridad de ambos países. Visto desde el discurso político y el comportamiento presidencial de Donald Trump, el gobierno de Cuba ha sido un excelente aliado en política migratoria. Visto por parte del Gobierno de Cuba, el fin de pies secos/pies mojados fue un triunfo diplomático y político también de su interés, que perdura eficazmente bajo la Administración Trump.

11 Narcotráfico. El informe anual del gobierno de EEUU sobre el narcotráfico en el ámbito mundial ya por muchos años refleja una realidad importante. El informe de comienzos de marzo de 2017, el primero concluido durante la Administración Trump, comenta que, a pesar de su ubicación geográfica perfecta para quien sea narcotraficante, «Cuba no es un consumidor, productor, o cruce importante de narcóticos ilícitos ${ }^{1} . »$ Produce poco, según el mismo informe, debido a las políticas de prevención, información, policiales, y judiciales del gobierno cubano. Cuba, además, «impide el contrabando a través de sus aguas territoriales» y en sus aeropuertos. «Los narcotraficantes de la región normalmente evitan pasar por Cuba» (U.S. Department of State, Bureau of International Narcotics, 2017, I: 142-143). Este texto del Gobierno de EEUU confirma la apreciación que éste tiene por las decisiones que el gobierno cubano, que por sus propias razones y unilateralmente con mucha anterioridad a este acuerdo y a la Administración Obama y la Administración Trump, ya había adoptado.

El 22 de julio de 2016, ambos gobiernos firmaron un acuerdo que les permite intercambiar información táctica sobre embarcaciones sospechadas de tráfico de drogas que cruzan las aguas territoriales cubanas (U.S. Embassy-Cuba, 2017). Establece por primera vez vínculos formales entre el Ministerio del Interior (MININT) y el U.S. Drug Enforcement Administration (DEA). Cuba y EEUU ya habían cooperado desde los 1990s para impedir y reprimir el narcotráfico. Las fuerzas de seguridad de ambos países ya de cuando en cuando intercambiaban información de inteligencia y participaban en operaciones conjuntas para capturar a narcotraficantes y disuadirles de utilizar los espacios marítimos o terrestres cubanos para sus propósitos criminales. A fines de los 1990s, bajo las presidencias de Fidel Castro y William Clinton, Cuba propuso formalizar y ampliar esta cooperación contra narcotraficantes, que por fin se firmó en julio de 2016 (Kornbluh P., 2000). A partir de ese nuevo acuerdo en julio de 2016, Cuba ha proveído, además, documentación, testigos, e información policial para facilitar que los tribunales de justicia, federal y estatales, logren proceder eficaz y judicialmente a procesar a los presuntos criminales (U.S. Department of State, Bureau of International Narcotics, 2017: I, 142).

Terrorismo. Durante su campaña presidencial, otra preocupación clave para Trump fue la violencia, terrorista o criminal, por parte de migrantes o de narcotraficantes. Los acuerdos sobre migración y narcotráfico ya permiten cooperación contra la violencia criminal. Además, desde 1973 Cuba y EEUU aplican un acuerdo contra la piratería aérea que, desde el momento de su firma, tuvo un impacto notable y casi instantáneo para eliminar ese fenómeno de los cielos sobre ambos países. Fue un logro de las presidencias de Richard Nixon y Fidel Castro. Cuba, blanco de múltiples atentados terroristas a través del tiempo, ha seguido intentando profundizar esta colaboración.

El Pentágono (DOD), el Comando Sur, el Departamento de Seguridad Nacional (DHS), los Guardacostas, que son las agencias responsables por los asuntos de seguridad y migración, todas apoyan la continuación de la bien establecida y mejorada relación con Cuba en materia de seguridad y migración, y así se lo han expresado a la Casa Blanca (Mazzei, P. et al., 2017). Esa coordinación entre estas agencias es una explicación 
importante de por qué las políticas hacia Cuba de la Administración Trump no han cambiado en estos aspectos.

\section{Relaciones Cuba-EEUU: Ventajas desproporcionadas para EEUU}

En dos aspectos de sus relaciones con Cuba, Estados Unidos logra que Cuba acepte una relación carente de balance, en búsqueda de objetivos de mayor prioridad para Cuba que cualquier equilibrio en abstracto. Se trata de agricultura y aviación civil.

16 A fines de 2001, la Administración Bush autorizó las exportaciones agrícolas de EEUU hacia Cuba, pero sin autorizar una contraparte de exportaciones cubanas hacia EEUU. Entre 2002 y 2016, EEUU exportó casi $\$ 5.6$ mil millones de dólares en productos y equipos agrícolas a Cuba; en 2016, el valor de este rubro fue de \$245 millones de dólares (U.S. Department of Commerce, 2017). El Presidente Trump, preocupado por el déficit en la balanza comercial, supuestamente alabaría esta marcada desproporción a favor de EEUU. La producción agrícola de Cuba es deficitaria; el mercado de Estados Unidos resultó ser una opción útil, y estas compras comerciales resultaron también ser una «inversión» política cubana para lograr apoyo en el Congreso de Estados Unidos.

El 16 de diciembre de 2015, los dos gobiernos llegaron a un acuerdo de aviación civil que amplió notablemente las opciones de vuelos de EEUU a Cuba. Los principales beneficiarios fueron personas de la diáspora cubana en EEUU que, ya en 2016, excedían el número de visitantes a Cuba de cualquier otro país excepto Canadá. El total visitantes a Cuba provenientes de EEUU excedió medio millón de personas en 2016 (Cuba, Oficina Nacional de Estadística e Información, 2016). Lo notable ha sido que Cubana de Aviación no vuela a EEUU. Solamente las líneas de aviación civil de Estados Unidos vuelan entre los dos países. Este segundo y más reciente desbalance en las relaciones económicas entre los dos países también se explica por el interés de Cuba de promover las visitas internacionales. Si Cubana de Aviación hubiera volado a EEUU, se hubiera provocado un conflicto en tribunales de justicia, desatado por quienes desearían expropiar los aviones de Cubana como compensación por propiedades expropiadas por el Gobierno de Cuba a comienzos de los 1960s. Más valioso era que el número de estos visitantes se incrementara, y por eso Cuba adoptó esa decisión, de otra manera tan favorable a las líneas de aviación de Estados Unidos.

\section{Relaciones Cuba-EEUU: Ventajas compartidas}

Los acuerdos en seguridad y migración claramente cumplen los objetivos y las prioridades de ambos gobiernos; han sido excelentes, pero no los únicos, ejemplos de ventajas compartidas entre los dos gobiernos.

Los acuerdos económicos logrados entre Cuba y Estados Unidos en 2015 y 2016 siguieron operando bajo el marco de las sanciones económicas que EEUU le ha impuesto a Cuba por varias décadas. El procedimiento por parte de EEUU durante estos dos años fue, según autoriza la ley, de permitir excepciones a su régimen de sanciones. En algunos casos, como las visitas internacionales y la aviación civil, la autorización excepcional liberalizó la relación notablemente. En otros casos, las trabas financieras y comerciales se mantuvieron a pesar de esfuerzos puntuales para resolver problemas 
concretos. Se permitían inversiones solamente por autorización específica, y ocurrieron algunas, pero pocas; algo similar ocurrió con relaciones comerciales, aunque se ampliaron algo más en los rubros de servicios. Este régimen de autorizaciones ha continuado durante la Administración Trump (Gámez Torres N., 2017).

Quizás el principal éxito empresarial, más allá de las líneas de aviación y las exportaciones agrícolas, ha sido Airbnb. Abrió en Cuba en abril de 2015; dos años después, había facilitado hospedaje a más de medio millón de personas en Cuba. Durante el primer semestre de la presidencia de Trump, hospedaba Airbnb en Cuba un promedio de 70,000 personas por mes.

21 La colaboración académica, nunca interrumpida del todo (EFE, 20172), produjo un salto cualitativo. Diversos Colleges y Universidades de Estados Unidos establecieron acuerdos con sus contrapartes en Cuba. Los acuerdos firmados por ambos gobiernos autorizaron y facilitaron la colaboración científica entre ambos países, inclusive de sus funcionarios. Se hizo hincapié en el medio ambiente, desde mejores intercambios de información meteorológica hasta expediciones conjuntas explorando la biodiversidad terrestre y marítima del archipiélago cubano.

Ejemplos de esta colaboración científica continuaron en 2017 bajo la Administración Trump. Por ejemplo, el 15 mayo de 2017 zarpó el barco «R/V F.G. Walton Smith», propiedad de la Universidad de Miami, abordo con especialistas de Cuba y EEUU, para circunnavegar el archipiélago cubano. El propósito de esta expedición científica conjunta fue estudiar la extensión de los arrecifes de coral profundos en el entorno del archipiélago. Duró más de cuatro semanas. Fue auspiciada en Cuba por el Acuario Nacional de Cuba, el Instituto de Ciencias del Mar, y el Centro Nacional de Áreas Protegidas, todos pertenecientes al Ministerio de Ciencia, Tecnología, y Medio Ambiente, así como el Centro de Investigaciones Marinas de la Universidad de La Habana, la Oficina de Regulaciones Pesqueras del Ministerio de la Industria Alimentaria, y el Grupo Empresarial Geocuba. Fue auspiciada en Estados Unidos, donde se le conocía como el programa, "Cuba's Twilight Zone Reefs and Their Regional Connectivity", por el U.S. National Oceanic and Atmospheric Administration (NOAA) y Florida Atlantic University. Un detalle que subraya la cordialidad en el seno de esta colaboración científica fue la decisión de NOAA de publicar en su página web no solamente breves artículos redactados por científicos estadounidenses sino también por científicos cubanos (Martínez Daranas B., 2017; González Díaz P., 2017).

23 La expedición se regía por el acuerdo firmado el 18 de noviembre del 2015 entre ambos gobiernos para cooperar en la conservación y manejo de áreas marítimas protegidas. Ese acuerdo, entre otros elementos, establecía un programa de «santuarios hermanos» entre los santuarios marinos de Guanahacabibes y San Antonio en Cuba y los santuarios marinos al sur de la Florida, Luisiana, y Texas (Reed J., 2017; Granma, 2017b). La nueva cooperación medio ambiental puede facilitar la protección de aves y peces migratorios que no requieren pasaporte ni visa para viajar de un país al otro.

\section{La manzana de la discordia: Democracia y derechos humanos}

El 3 de mayo de 2017, el Secretario de Estado Rex Tillerson se reunió con un amplio grupo de funcionarios del Departamento de Estado para explicar la nueva política 
exterior mundial de Estados Unidos. Entre otros asuntos, se refirió al tema de derechos humanos. «Si se subordinan nuestros esfuerzos sobre seguridad nacional a que otro adopte nuestros valores, probablemente no lograríamos éxitos con nuestros propósitos de seguridad nacional o de servir nuestros intereses en seguridad nacional.» Añadió Tillerson, «en algunas circunstancias, debemos y así lo hacemos, subordinar nuestras relaciones y políticas a que otros adopten cierto comportamiento en el trato de su pueblo... y debemos exigir eso, pero no quiere decir en todo caso y en toda situación» (U.S. Department of State, Diplomacy in Action, 2017).

Un mes después, el 5 de junio, en una conferencia de prensa en la Casa Blanca, el Portavoz Presidencial Sean Spicer contestaba una pregunta en que el periodista recordaba la loa del Presidente Trump al Presidente Rodrigo Duterte, Filipinas, a pesar de las duras críticas por graves violaciones de derechos humanos que se han presentado contra Duterte. El Portavoz Spicer señalaba que el Presidente Trump alabó al Presidente Duterte por la lucha contra el narcotráfico pero, según Spicer, Trump «también cree en derechos humanos... es una de las razones por lo que está revisando la política hacia Cuba...» (White House, Office of the Press Secretary, 2017a).

Estos dos textos proveen una buena explicación. Precisamente porque Cuba no es particularmente importante para Trump, puede la Casa Blanca darse el lujo de formular una política hacia Cuba que haga hincapié en el tema de democracia y derechos humanos. Y este bajo perfil estratégico es lo que permite que actores de política interna de EEUU incidan en el diseño de la política de EEUU hacia Cuba, es decir, que los Senadores y Diputados cubano-americanos que representan los criterios ya solamente de una minoría de la comunidad cubano-americana en EEUU logren una modificación de la política hacia Cuba.

Además, si este análisis acierta, implica que Cuba mantiene tal interés en cooperar con EEUU en migración, narcotráfico, y terrorismo que no cancelaría por sí sola estos acuerdos, a pesar de que a su gobierno no le guste una nueva política de EEUU hacia Cuba que enfatice democracia y derechos humanos.

El 16 de junio de 2017 el Presidente Trump anunció su política hacia Cuba en cuatro partes. Primero fue un gran espectáculo visual. El anuncio por parte del presidente ocurrió en la llamada «Pequeña Habana» en Miami, rodeado por los congresistas cubano-americanos, y frente a los veteranos de la Brigada 2506 que invadió Playa Girón, Bahía de Cochinos, Cuba, en abril de 1961. Su principal propósito fue permitirle al presidente decir, "cumplo mis promesas,» ya que los veteranos de la Brigada lo apoyaron públicamente durante su campaña presidencial. Proclamó el presidente, «Por tanto, con efecto inmediato, cancelo el acuerdo, totalmente favorable para Cuba, que data de la administración pasada» (White House, Office of the Press Secretary, 2017b).

Un segundo elemento, sin embargo, fue mantener la autorización de todas las políticas que he discutido en este artículo, es decir, las colaboraciones en el ámbito militar, policial, migratorio, y contra el tráfico de drogas, así como los acuerdos sobre aviación civil, medio ambiente, exportaciones agrícolas estadounidenses, flujo de remesas, y «visitas» internacionales que excluía visitas a las playas (que fue siempre la política de la Administración Obama).

Tercero, pues, ¿qué cambió ese 16 de junio? La respuesta más común era el refrán, «Los cambios anunciados no entran en vigor hasta que no se publiquen formalmente las nuevas regulaciones.» Meses después, seguimos en espera. Las batallas burocráticas y 
políticas, quizás más que el contenido de las relaciones bilaterales, determinarán qué habría de nuevo, cuándo, y cómo. El cambio más probable es la eliminación de los viajes individuales, y la estancia en un número de hoteles, pero permitiendo los viajes auspiciados por entidades, asociaciones, y agencias de viaje y las estancias mediante Airbnb; esta hipótesis requiere, sin embargo, que continúe la posibilidad de obtener visas en ambas direcciones, procesos que, como señalo en la sección que sigue y que trata de opciones, puede quedar entorpecido.

El cuarto aspecto fue anunciar, en ese mismo discurso del 16 de junio, la disposición de negociar. Señaló sus prioridades: la devolución de un fugitivo de la justicia estadounidense, la liberación de presos políticos, y otros «pasos concretos».

¿Cuáles son, pues, los instrumentos del Gobierno de EEUU para promover los valores democráticos y los derechos humanos en Cuba? Por muchos años, un instrumento de la política de EEUU hacia Cuba ha sido el presupuesto del U.S. Agency for International Development (AID) para promover democracia y derechos humanos en Cuba. El presupuesto de la AID para estos programas con relación a Cuba, bajo la Administración Obama, fue de $\$ 20$ millones de dólares para el Año Fiscal 2016 (cerró el 30 de septiembre de 2016). La primera propuesta de este presupuesto de la Administración Trump, es decir, para el Año Fiscal 2018 que comenzó el primero de octubre de 2017, fue de $\$ 0$. Es probable que el Congreso de EEUU restaurará parte de, o todos, estos fondos, pero la propuesta presupuestal revela el pensamiento de la Casa Blanca y de su oficina presupuestaria (U.S. Department of State, «Congressional Budget Justification» 2017:88). Esta solicitud presupuestaria se publicó el 23 de mayo de 2017, es decir, pocos días antes del mensaje del Presidente Trump del 16 de junio.

Es posible que la lógica de recortes al presupuesto se impusiera. Estos programas de la AID recibían, además, fuertes críticas por ser ineficaces y a veces contraproducentes; es posible que en el mismo Departamento de Estado y en la AID no hubiera una defensa verdadera de este presupuesto. Pero no deja de sorprender que la Administración cancelara estos programas.

\section{Opciones}

¿Cuáles son las posibilidades de nuevas negociaciones a las que se refirió el Presidente Trump el 16 de junio de 2017?

\section{Opción 0. Pasa poco}

No perdurará el tono conciliador de los dos últimos años de la presidencia de Obama; resurgirán asperezas en público y en las negociaciones confidenciales. Se repetirán críticas al desempeño del gobierno cubano con relación al respeto por los derechos humanos en Cuba, probablemente en efemérides tales como el 24 de febrero, el 20 de mayo, y el 10 de octubre. Además, las quejas con respecto a la política de Obama hacia Cuba, citadas por Trump y quienes se interesan por el tema Cuba en sus círculos políticos, subrayan que Obama no obtuvo «concesiones» del gobierno cubano a cambio de las «concesiones» hechas por EEUU a Cuba. Habrán referencias, en singular, al «mal acuerdo de Obama,» omitiendo referencias, en plural, al par de docenas de muy buenos acuerdos logrados bajo Barack Obama y Raúl Castro. Se promulgarán nuevas regulaciones que prohibirán los viajes «individuales» y estancias en ciertos hoteles, 
pero se mantendrá la autorización para los demás tipos de viajes y facilidades de hospedaje. adversarios. Cambiará por tanto la forma de proceder. Al final de la presidencia de Obama, el Gobierno de EEUU negociaba tema por tema, circunscribiendo cada negociación a los aspectos técnicos inherentes de ese tema. La Administración Trump estará más dispuesta a vincular diversos temas en una misma negociación, entre otros derechos humanos y régimen político en Cuba. el gobierno cubano, que insiste que no hace ni hará concesiones. La Administración Obama no se jactó de extraer concesiones del gobierno cubano. Sin embargo, recordemos el 17 de diciembre de 2014 cuando los Presidentes Barack Obama y Raúl Castro simultáneamente, en sus respectivas ciudades capitales, anunciaron el cambio en las relaciones bilaterales. En su alocución a sus conciudadanos, el Presidente Castro anunció también: «De manera unilateral, como es nuestra práctica y en estricto apego a nuestro ordenamiento legal, han recibido beneficios penales los reclusos correspondientes, incluida la excarcelación de personas sobre las que el Gobierno de los Estados Unidos había mostrado interés» (Granma, 2014). Es decir, ¿concesiones? Por supuesto que no. ¿Gesto unilateral que le permite al Presidente de EEUU un éxito en su política con relación a derechos humanos en Cuba? Por supuesto que sí.

\section{Opción 1. Realista, ya visible}

Opción Realista es deseable tanto para el Gobierno de EEUU como para el Gobierno de Cuba. Reafirmaría, en voz baja, la validez y la importancia de los acuerdos formales e informales con relación a la seguridad en el entorno de la base de EEUU cerca de Guantánamo y en el Estrecho de la Florida, en particular el control migratorio, y la lucha contra los narcotraficantes, la violencia criminal, y el terrorismo. Sobreviviría la autorización de exportación a Cuba de productos agrícolas estadounidenses. Todas estas políticas se crearon y estuvieron en vigor antes de la presidencia de Obama.

Igualmente realista es, sin embargo, que la Administración Trump modifique algún elemento de la política de la Administración Obama hacia Cuba ya que el candidato Trump había prometido revertirla. Esto sugiere que se mantendría el retorno al discurso ideologizado sobre derechos humanos y democracia y se abre la posibilidad de una ruptura de relaciones diplomáticas.

Entre el otoño de 2016 y mediados de 2017, diplomáticos estadounidenses y canadienses, en sus respectivas sedes en La Habana, fueron víctima de ataques sónicos que, en los casos más graves, pueden haber provocado daños cerebrales permanentes. No se ha descubierto cómo ni por qué ocurrió, a pesar de la cooperación profesional entre ambos gobiernos, pero este hecho no ha impedido que los congresistas cubanoamericanos soliciten la ruptura de relaciones diplomáticas.

41 Tal ruptura tendría un fuerte valor simbólico y político - cumple Trump sus promesas de campaña presidencial -- con pocas consecuencias prácticas adversas. Los principales acuerdos en seguridad y migración y las exportaciones agrícolas se lograron antes del restablecimiento de las relaciones diplomáticas y podrán continuar si se rompen tales relaciones. Las respectivas embajadas se reducirían una vez más a Secciones de Interés, 
bajo la responsabilidad formal de la Confederación Suiza. El número de personal diplomático y consular puede seguir siendo igual.

Para fines de 2017 la Administración Trump no había roto relaciones diplomáticas pero, en respuesta a la falta de resolución del problema de los ataques sónicos a sus diplomáticos (¿cómo ocurrió? ¿por qué ocurrió? ¿quién es responsable?), redujo su personal diplomático y consular en su embajada en La Habana y exigió una reducción proporcional del personal diplomático y consular cubano de la embajada de Cuba en Washington. Al mismo tiempo, insistió que eran simplemente medidas de seguridad para la protección de sus diplomáticos y no modificaban el contenido de las relaciones bilaterales, tal como describe este artículo.

El impacto más directo de estas medidas, si no se revierten, sería una notable reducción de las visitas de cubanos a EEUU y una posible reducción de las visitas de estadounidenses a Cuba. La principal diferencia entre los dos flujos se explica por los procedimientos de cada país para otorgar los permisos pertinentes. EEUU exige una entrevista personal de cara a cara previa a la concesión de una visa. Si no hay personal consular para realizar estas entrevistas en su embajada en La Habana, se requeriría que cada solicitante viaje a un tercer país para esa entrevista en algún otro Consulado de EEUU (v.g., en Bogotá, en la Ciudad de México, etc.), encareciendo así el costo de obtener una visa (viaje aéreo, hospedaje en hotel, etc.). Cuba no exige una entrevista personal. Puede por tanto autorizar a agencias de viajes en EEUU que presenten las solicitudes de visa a Consulados de Cuba en otros países (v.g. en Toronto, en la Ciudad de México, etc.), permitiendo así la continuación de las visitas de estadounidenses a Cuba.

La continuación de la reducción de personal consular y diplomático en las respectivas embajadas en La Habana y Washington, por supuesto, entorpecería las relaciones entre los dos gobiernos y los dos países. Una solución razonable presume que no se descubrirá la respuesta a las preguntas que generan incertidumbres pero, con vista al futuro, Cuba permitiría la presencia permanente en la embajada de EEUU en La Habana de personal del FBI, entrelazados profesionalmente con su contraparte en el MININT. El FBI no había podido actuar en La Habana por medio siglo, regresando por vez primera precisamente para investigar los ataques sónicos; la modificación por tanto sería pasar de esa autorización ad hoc a una autorización institucionalizada.

Acotaciones. Como ya se señaló, la Administración Obama cambió fundamentalmente la política migratoria de EEUU hacia Cuba en una dirección que parece reflejar nítidamente las propias preferencias del Presidente Trump en política migratoria. La Administración Trump tendrá que decidir, sin embargo, si se siguen aplicando los notables incrementos de cooperación en materia de seguridad negociados bajo Obama. El 14 de octubre de 2016, el Presidente Obama emitió su decisión más abarcadora y completa que resumía su política hacia Cuba. Entre los elementos de esa decisión encontramos los siguientes (White House, 2016):

«El Departamento de Defensa (DOD) apoyará la inclusión de Cuba en el sistema inter-Americano de defensa y en las conferencias regionales de seguridad y defensa...»

«...El Departamento de Seguridad Nacional (DHS) desarrollará protocolos de investigación cooperativa con Cuba...»

«El Departamento de Justicia (DOJ) trabajará, conjuntamente con DHS, con el gobierno cubano para combatir al terrorismo y al crimen transnacional organizado. El DOJ trabajará con Cuba para expandir la cooperación en seguridad y 
cumplimiento de la ley, aumentar el intercambio de información... ampliando y

fortaleciendo la cooperación que ya existe con Cuba...» cooperación militar con Cuba debe suspenderse, o por lo menos restringirse, a las áreas que existían antes de los acuerdos logrados durante 2015 y 2016. Estados Unidos, según tal crítica, no debe colaborar con el gobierno de un régimen político autoritario. Se eliminaría así el intercambio de información en materia de seguridad, las investigaciones cooperativas, y la opción de participación de Cuba en el sistema interAmericano de defensa y sus conferencias. Tal decisión reduciría sensiblemente la cooperación contra el crimen transnacional y el narcotráfico, que requieren intercambios de información y cooperación en la investigación. Podría además dificultar el retorno a Cuba de migrantes cubanos indocumentados que ingresan a EEUU por avión o por tierra, ya que el acuerdo con relación a ese retorno requiere intercambio de información.

El personal uniformado en DOD y DHS desea continuar la cooperación en seguridad y migración tal como se logró durante la Administración Obama. Se oponen a las restricciones concebibles. Sin embargo, este aspecto de la alianza Cuba-EEUU en materia de seguridad y migración es también un ámbito de posible cambio en las relaciones bilaterales donde, además, se logrará observar la lucha por el control y dirección de la política hacia Cuba.

Por parte del gobierno de Cuba, la decisión clave es decidir si, según su interés nacional y soberano, sigue siendo preferible cooperar con EEUU en materia de seguridad y migración a pesar de que la Administración Trump gire rumbo a una política hacia Cuba que, en su dimensión ideológica, retorne al tema de derechos humanos y democracia como prioridad discursiva, en particular si además se rompen las relaciones diplomáticas o se entorpecen los intercambios por la dificultad de obtener visas, justificando esas decisiones bajo el alegato que Cuba no respeta los derechos humanos y carece de un régimen político democrático. Como corolario, puede requerir también decidir, en caso de que se apliquen las restricciones posibles en la cooperación en seguridad, si es mejor continuar con lo que ya se había logrado a pesar de nuevas restricciones. Según el análisis expuesto en páginas anteriores, creo que el gobierno cubano preferiría la cooperación en seguridad y migración en vez de retornar a una confrontación mucho más grave.

La respuesta del gobierno cubano a la nueva política de la Administración Trump ha sido notable por su moderación. Reitera su disposición de dialogar y cooperar con EEUU en asuntos de interés mutuo, y de seguir negociando sobre otros temas pendientes de interés bilateral. El canciller ratificó que Cuba cumplirá los acuerdos que se han firmado, y que sigue dispuesta a negociar, aunque no sobre el diseño de su propio sistema político. Recordó, en alusión al discurso del Presidente Trump del 16 de junio de 2017, que Cuba ha repatriado criminales a EEUU, por su decisión unilateral y consecuente con las leyes cubanas (Granma, 2017a).

Esa respuesta oficial cubana fue probablemente anticipada por el gobierno de EEUU. Por tanto, la Administración Trump se siente libre de retornar al discurso de derechos humanos y democracia, inclusive romper relaciones diplomáticas y entorpecer los intercambios y las visitas no oficiales mediante las crecientes dificultades para obtener visas, y aplicar ciertas restricciones a la cooperación en seguridad, bajo el supuesto de que Cuba se quejaría, pero lo aceptaría. Los logros prácticos de una reanudada 
confrontación serían nulos; se detendría claramente la opción de ampliar o mejorar la cooperación construida. Sin embargo, el logro simbólico y político para la Administración Trump - cumplir con sus promesas de campaña de revertir la política de Obama hacia Cuba - lo justificaría. Cuba a regañadientes probablemente lo aceptaría.

\section{Opción 2. Posible}

51 El sesgo mercantilista de Donald Trump no solamente puede ver bien la exportación de productos agrícolas a Cuba, sin contraparte de importación de Cuba, sino también el acuerdo de aviación civil, precisamente porque en la práctica le es tan favorable a las líneas de aviación de EEUU. Trump puede confirmar otros acuerdos o procesos de negociación comenzados desde diciembre de 2014 porque los beneficios de muchos acuerdos ya negociados son necesariamente compartidos (v.g., el funcionamiento del correo, el intercambio de información sobre huracanes, o la protección de especies migratorias).

52 La Opción Posible y los aspectos de seguridad y migración en la Opción Realista, todos puramente pragmáticos, contribuyen en parte a comprender por qué, al concluir el primer año de la Administración Trump, no hubo cambios dramáticos en su política hacia Cuba. Los funcionarios de carrera reconocían el valor de lo logrado por la Administración Obama, y lo absurdo de la queja que no se obtuvo «concesiones».

\section{Opción 3. Osada}

53 La Opción Osada es que Trump, en pro de la mayor "prosperidad y libertad» para el pueblo cubano, que resaltó en su comentario después de la muerte de Fidel Castro (Rampton R., 2016), impulse algunas medidas ya autorizadas por Obama. Carente como ya expliqué de instrumentos más allá de lo retórico para promover los derechos humanos en Cuba, la Administración Trump puede decidir que Obama no se había equivocado: se puede continuar con la política de Obama sin decirlo de esa manera.

¿Qué buscaba Obama? Que Cuba y los cubanos imaginaran y diseñaran un futuro mejor. ¿Cómo promover un cambio libertario en Cuba? Permitiendo que los cubanos se independicen económicamente del Estado. ¿Qué puede hacer EEUU para impulsar medidas de creación de un sector privado en la economía cubana, bajo la «actualización del socialismo» en Cuba autorizado por el VI Congreso del Partido Comunista de Cuba (PCC) en 2011 y ratificado por el VII Congreso del PCC en 2016? Facilitar las visitas de los cubanoamericanos para que conversen con sus parientes y sus amigos sobre un futuro distinto, y que envíen remesas no solo para la supervivencia de los suyos sino también para invertir en pequeñas empresas, ahora legales. ¿Cómo ampliar el mercado para el sector privado? Permitir las visitas de cientos de miles de estadounidenses por año, que concurran a restaurantes privados (paladares), paladines de este nuevo sector privado que compran productos a campesinos; así, tanto paladares como campesinos se independizan de la tutela del Estado. ¿Cómo evitar que estas visitas internacionales redunden en desmesurados beneficios para el Estado cubano? Retener la prohibición del turismo de playa. Así se impide el control que los enclaves playeros han construido y facilitado sobre los canadienses y otros turistas que allí acuden. Congrega a los estadounidenses en ciudades, intercambiando directamente con sus contrapartes cubanos. Permitir la continuación y prosperidad de Airbnb, que canaliza a los visitantes 
internacionales a domicilios privados, no a hoteles que sean empresas mixtas con el Estado; con un monto de ingresos de $\$ 40$ millones de dólares en un par de años, este sectorcillo privado ha creado un espacio social de clase media urbana autónoma (EFE, 2017). De ese sector económico privado y sus corolarios resurge como un Fénix una nueva sociedad civil en Cuba, independiente del Estado, y capaz de facilitar otros cambios en pro de la «prosperidad y la libertad». Hay mayor libertad de información si se facilitan las telecomunicaciones y el más fácil acceso al Internet. Hay más libertad y prosperidad si EEUU amplía las relaciones económicas con el sector privado en Cuba. Estas y otras posibles oportunidades requieren que el Ejecutivo en EEUU elimine las trabas que perduran para una relación normal entre bancos en EEUU y en Cuba, permitiendo de hecho el uso del dólar y de las tarjetas de crédito. ¿Adoptaría esta política la Administración Trump?

Por parte del gobierno de Cuba, ese rumbo, quizás improbable pero sin duda osado por parte de la Administración Trump, es consistente con la estrategia económica imperante durante ya casi tres décadas. Fue Fidel Castro quien inició el impulso al turismo y quien inició la autorización de un pequeño sector privado. Puede a la dirección nacional de Cuba disgustarle tal motivación por parte del gobierno de EEUU, pero ese es un reto asumido por el gobierno cubano y el PCC durante esta década. Es por tanto imaginable que, si la Administración Trump autoriza el retorno de diplomáticos y cónsules a las respectivas embajadas, permite la continuación de los viajes internacionales, la aviación civil, y las remesas, al gobierno de Cuba no le quede remedio que aceptar la Opción Osada y asumir ese riesgo.

\section{Conclusión}

Cuba ha cooperado eficazmente y por muchos años con EEUU en los asuntos que parecen ser de prioridad para Trump. Esas bases de una razonable relación bilateral sirven para construir una cooperación profesional entre los dos gobiernos. Por tanto, el gobierno cubano no debe paralizarse por la reaparición de lo que he llamado la Opción 0. Debe buscar retener los logros compartidos y positivos en la Opción Realista sin caer en una guerra retórica con los tweets del Presidente Trump, en particular si el cumplimiento de sus promesas de campaña se circunscribe al ámbito discursivo, mientras que se busca un acuerdo razonable que permita el retorno de diplomáticos y cónsules a las respectivas embajadas. Debe insistir en lo que he llamado la Opción Posible, y debe reconocer los importantes aspectos positivos, así como el reto en la Opción Osada. Ese comportamiento permitiría aplicar a la relación entre Cuba y EEUU el mismo criterio que el Presidente Raúl Castro ha citado en otros contextos, es decir, proceder hacia un resultado bilateral eventualmente razonable para ambos gobiernos, «sin pausa, pero sin prisa». 


\section{BIBLIOGRAFÍA}

Castro Ruz, Raúl, «Comparecencia televisiva», Noticiero dominical, NTV, Cuba, 20 de enero de 2002.

Cuba, Oficina Nacional de Estadística e Información, «Turismo internacional: Indicadores Seleccionados», junio 2016, http://www.onei.cu/publicaciones/06turismoycomercio/ indturismointernac/publicacionmar16.pdf

página consultada el 8 de junio de 2017.

EFE, «Los cubanos ganaron unos $\$ 40$ millones gracias a Airbnb en dos años», EFE, 5 de junio de 2017, https://www.efe.com/efe/america/economia/los-cubanos-ganaron-unos-40-millones-dedolares-gracias-a-airbnb-en-dos-anos/20000011-3287998, página consultada el 5 de junio de 2017.

Gámez Torres, Nora, «Trump Administration Continues to Issue OFAC Licenses Authorizing Business with Cuba», The Miami Herald, April 4, 2017, http://www.miamiherald.com/news/ nation-world/world/americas/cuba/article142485889.html, página consultada el 31 de octubre de 2017.

González Díaz, Patricia, «Banco de San Antonio», NOAAOcean Explorer, 21 de mayo 2017, http:// oceanexplorer.noaa.gov/explorations/17cuba-reefs/logs/may21/may21-sp.html, página consultada el 9 de junio de 2017

Granma, «Alocución del presidente cubano, Raúl Castro», Granma, 17 de diciembre de 2014, http://www.granma.cu/cuba/2014-12-17/alocucion-del-presidente-cubano-raul-castro, página consultada el 18 de diciembre de 2014.

Granma, (a) «Declaración del Gobierno Revolucionario,» Granma, 17 de junio de 2017, http:// www.granma.cu/cuba/2017-06-16/declaracion-del-gobierno-revolucionario , página consultada del 18 de junio de 2017.

Granma, (b) «Expedición conjunta Cuba-Estados Unidos», Granma, 20 de mayo de 2017,

http://www.granma.cu/cuba/2017-05-19/expedicion-cientifica-conjunta-cuba-estadosunidos-19-05-2017-23-05-54, página consultada el 31 de octubre de 2017.

Kornbluh, Peter, «Cuba, Counternarcotics, and Collaboration: A Security Issue in U.S.-Cuban Relations», Cuba Briefing Paper Series, no 24, Washington, DC, Georgetown University, 2000.

Martínez Daranas, Beatriz, «Deep Seaweeds Scene,» NOAA Ocean Explorer, 3 de junio de 2017, http://oceanexplorer.noaa.gov/explorations/17cuba-reefs/logs/june3/june3.html página consultada el 9 de junio de 2017.

Mazzei, Paricia, Nora Gámez Torres y Anita Kumar, «How Cuba Policy and Its Inevitable Drama Ensnared Trump's White House», The Miami Herald, primero de junio de 2017,

http://www.miamiherald.com/news/nation-world/world/americas/cuba/ article153885819.html, página consultada el 6 de junio de 2017.

Public Law 89-732, 80 Stat. Public Law 89-732, noviembre 2, 1966, page 1161, https:// www.gpo.gov/fdsys/pkg/STATUTE-80/pdf/STATUTE-80-Pg1161.pdf

Rampton, Roberta, «After Castro Death, Trump Says Hopes for Cuban 'Freedom'», Reuters, https://www.yahoo.com/news/u-president-elect-trump-twitter-fidel-castro-death página consultada el 26 de noviembre de 2016. 
Reed, John, «Cuba's Twilight Zone Reefs and Their Regional Connectivity: Mission Plan,» NOAA Ocean Explorer, http://oceanexplorer.noaa.gov/explorations/17cuba-reefs/welcome.html, página consultada el 9 de junio de 2017.

«Statement by the Government of Cuba to the National and International Public Opinion», 11 de enero de 2002, cortesía de la Sección de Intereses de Cuba en Washington, DC.

U.S. Department of Commerce, International Trade Administration, 2017, http://tse.export.gov/ TSE/HTMLOnlyTableDisplay.aspx?COL=4\&DESC=true, página consultada el 8 de junio de 2017.

U.S. Department of Homeland Security, «Joint Statement between Government of the United States and Cuba», 2017, https://www.dhs.gov/sites/default/files/publications/ Joint\%20Statement\%20FINAL\%20-\%20US\%20alt.pdf, página consultada el 8 de junio de 2017.

U.S. Department of State, Bureau of International Narcotics and Law Enforcement Affairs, 2017 International Narcotics Control Strategy Report, 2017, https://www.state.gov/documents/ organization/268025.pdf, página consultada del 8 de junio de 2017.

U.S. Department of State, «Congressional Budget Justification, Foreign Assistance: Supplementary Tables, Fiscal Year 2018», https://www.state.gov/documents/organization/271014.pdf, página consultada el 8 de junio de 2017.

U.S. Department of State, Diplomacy in Action, Secretary of State Rex W. Tillerson, «Remarks to U.S. Department of State Employees», 3 de mayo de 2017, https://www.state.gov/secretary/ remarks/2017/05/270620.htm, página consultada del 8 de mayo de 2017.

U.S. Embassy-Cuba, «Counternarcotics Arrangement Signed During Third Counternarcotics Technical Exchange Between the United States and Cuba», 22 de julio de 2016, https:// cu.usembassy.gov/counternarcotics-arrangement-signed-third-counternarcotics-technicalexchange-united-states-cuba/, página consultada el 8 de junio de 2017.

White House, «Presidential Policy Directive - United States-Cuba Normalization», 14 de octubre de 2016, http://www.whitehouse.gov/the-press-office/2016/10/14/presidential-policy-directiveunited-states-cuba-normalization, página consultada el 14 de octubre de 2016.

White House, Office of the Press Secretary, (a) «Daily Press Briefing by Press Secretary Sean Spicer -- \#51», James S. Brady Press Briefing Room, 30 de mayo de 2017, https:// www.whitehouse.gov/the-press-office/2017/05/30/daily-press-briefing-press-secretary-seanspicer-51, página consultada el 5 de junio de 2017.

White House, Office of the Press Secretary, (b) «Remarks by President Trump on the Policy of the United States towards Cuba», 16 de junio de 2017,

https://www.whitehouse.gov/the-press-office/2017/06/16/remarks-president-trump-policyunited-states-towards-cuba, página consultada el 16 de junio de 2017.

\section{NOTAS}

1. Todas las traducciones al español son mías, a no ser que se indique otra fuente.

2. Las relaciones bilaterales, académicas y científicas, se redujeron notablemente durante la Administración George W. Bush, pero algunas sobrevivieron. Por ejemplo, Harvard University lanzó en 2005 y retuvo sin interrupción un programa para facilitar que sus estudiantes de College pudieran estudiar por un semestre en la Universidad de La Habana. Harvard mantuvo también su compromiso de auspiciar talleres de trabajo en La Habana y Cambridge, y facilitar la publicación de sus resultados. 


\section{RESÚMENES}

La política hacia Cuba posee baja prioridad en la Administración Trump. Su elemento más importante ha sido la continuación de una alianza entre Cuba y Estados Unidos en materia de seguridad y migración, que ya data de dos décadas, ampliada durante la Administración Obama. Las principales innovaciones en la relación Cuba-EEUU bajo la Administración Obama produjeron ventajas compartidas entre los dos países, o ventajas que desproporcionalmente favorecían a EEUU. Una innovación bajo la Administración Trump será un nuevo hincapié ideologizado del tema de derechos humanos, aplicado a Cuba precisamente porque carece de importancia para EEUU en el ámbito mundial. Se examinan opciones para la evolución de las relaciones bilaterales, que combinan el pragmatismo de cooperación práctica y el retorno a una confrontación ideológica que puede conllevar a la ruptura de relaciones diplomáticas.

Cuba policy has low priority for the Trump Administration. Its key element has been the continuation of a U.S.-Cuba Alliance regarding security and migration, begun two decades ago and expanded during the Obama Administration. The Obama Administration's main innovations regarding the U.S.-Cuba relationship yielded joint gains between the two countries or gains that disproportionately benefited the United States. A Trump Administration innovation will be a new ideologized emphasis concerning the human rights issue, to be applied to Cuba precisely because it lacks worldwide importance for the United States. Options regarding the evolution of bilateral relations are considered, combining the pragmatism of practical cooperation and the return to an ideological confrontation that may lead to a break in diplomatic relations.

La relation avec Cuba est loin de représenter une priorité pour l'Administration Trump. Elle se résume essentiellement à la poursuite d'une alliance entre les deux pays sur les questions de sécurité et de migration, entamée il y a deux décennies et élargie pendant l'Administration Obama. Les principales innovations entreprises par celle-ci dans le cadre de la relation bilatérale ont abouti à des avantages équitablement répartis entre les deux pays ou bien à d'autres qui profitent de manière disproportionnée aux seuls Etats-Unis. La nouveauté, sous l'Administration Trump, consiste à renouer avec l'accent idéologique mis sur la question des droits de l'homme, appliquée spécifiquement à Cuba, précisément parce que celle-ci ne revêt pas d'importance stratégique internationale pour les Etats-Unis. L'évolution de la relation bilatérale dépendra des options actuellement à l'étude, associant le pragmatisme d'une coopération d'ordre pratique et le retour à une confrontation idéologique susceptible de conduire à une rupture des relations diplomatiques.

\section{ÍNDICE}

Mots-clés: Trump, Raúl Castro, sécurité, migration, droits de l'homme

Palabras claves: Trump, Raúl Castro, seguridad, migración, derechos humanos

Keywords: Trump, Raúl Castro, security, migration, human rights 


\section{AUTOR}

\section{JORGE I. DOMÍNGUEZ}

Jorge I. Domínguez es profesor de ciencias políticas en la Universidad de Harvard (Harvard University, 1737 Cambridge St., Cambridge, MA 02138 USA, Jorge_Domínguez@harvard.edu).Ha sido vicerrector de la Universidad para los asuntos internacionales y presidente del Latin American Studies Association (LASA). Con R. Hernández y L. Barberia, es compilador de y autor en Debating U.S.-Cuban Relations: Shall We Play Ball (Routledge, 2017). 